\title{
Budget Rigidity and Expenditure Efficiency in Slovenia
}

\author{
Todd Mattina and Victoria Gunnarsson
}





\title{
IMF Working Paper
}

Fiscal Affairs Department

\section{Budget Rigidity and Expenditure Efficiency in Slovenia}

\section{Prepared by Todd Mattina and Victoria Gunnarsson}

Authorized for distribution by Gerd Schwartz

June 2007

\begin{abstract}
This Working Paper should not be reported as representing the views of the IMF. The views expressed in this Working Paper are those of the author(s) and do not necessarily represent those of the IMF or IMF policy. Working Papers describe research in progress by the author(s) and are published to elicit comments and to further debate.

This paper assesses the relative efficiency and flexibility of public spending in Slovenia compared to the advanced and new EU member states. Spending on health care, education, and social protection is relatively high in Slovenia without achieving correspondingly better outcomes. Inefficiencies appear to stem from the financing mechanisms for social services, institutional arrangements, and the weak targeting of social benefits. In addition, the composition of spending appears to be strongly tilted towards nondiscretionary items that reduce the fiscal room for maneuver. Greater flexibility is needed to facilitate the reallocation of relatively inefficient expenditure into higher priorities. In this manner, medium-term expenditure rationalization can focus on reducing inefficient outlays rather than restraining traditionally flexible components of the budget, such as public investment.
\end{abstract}

JEL Classification Numbers:H11, H51, H52, H53

Keywords: Public expenditure efficiency; flexibility of spending

Authors’ E-Mail Addresses: tmattina@imf.org; vgunnarsson@imf.org 


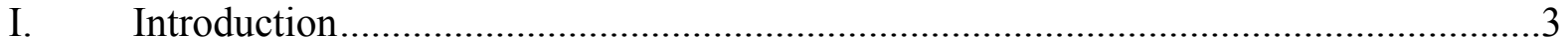

II. Stylized Facts and Key Issues...................................................................

III. Assessing Efficiency as a Benchmark to Guide Expenditure Rationalization .............8

IV. Sources of Budget Rigidity in Slovenia ......................................................... 19

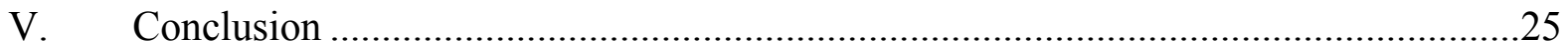

Tables

1. Variation in Key Expenditure Categories, 2000-05 .......................................................

2. Multiple Outcome Health Sector Efficiency Model .................................................. 13

3. Multiple Outcome Education Efficiency Model............................................................17

4. Impact of Social Benefits in Reducing Earnings Inequality ...........................................18

5. Variation in Primary Spending and the Output Gap, 2000-05 ......................................20

6. Benefit and Duration of Key Social Benefits in Selected EU Countries ...........................23

Figures

1. Slovenia: Composition of Expenditure Adjustment, 2000-05 ......................................5

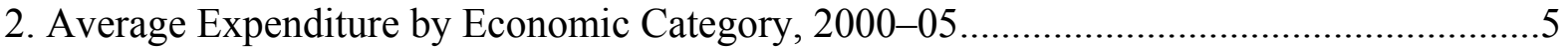

3. Comparison of Major Functional Spending Categories, 2004 ......................................6

4: Discretionary and Nondiscretionary Share of Expenditure ..........................................8

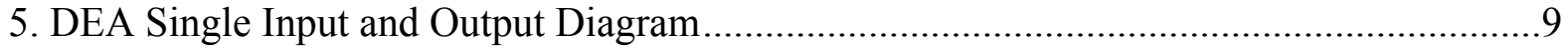

6. Efficiency of Public Spending in Reducing Child Mortality ..........................................11

7. Efficiency of Primary Education in Lowering the Student-Teacher Ratio.........................15

8. Slovenia: Composition of General Government Health Spending, 2000-04 ....................21

Appendixes

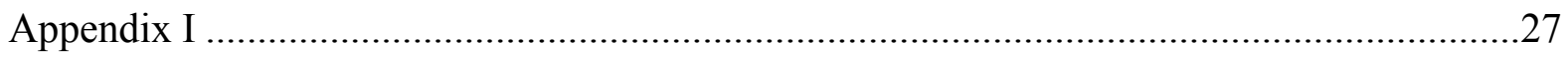

Appendix Tables

A1. Time Period and Country Coverage of DEA Models ...................................................27

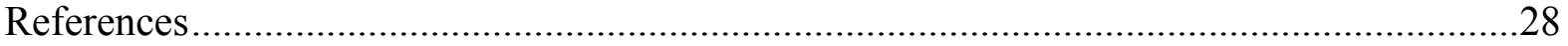




\section{INTRODUCTION}

Slovenia is facing a sharp increase in age-related spending, estimated to reach 8 percent of GDP by 2050 . To help ease this pressure, the authorities envisage rationalizing public expenditure over the medium term. This paper applies a cross-country technique to identify relatively inefficient spending on health, education and social protection as a tool to guide expenditure rationalization. Successful implementation of this strategy will require greater budget flexibility so that spending cuts can target relatively inefficient spending without compromising the quality of public services. Euro adoption in 2007 also places a premium on greater budget flexibility to help accommodate shocks. By enhancing the flexibility of expenditure, Slovenia can avoid distortionary across-the-board cuts or excessive restraint in traditionally flexible areas, such as capital investment and other goods and services. ${ }^{1}$

This paper assesses the efficiency of public spending by comparing expenditure on health, education and social protection to outcome indicators, such as mortality rates, standardized test scores and poverty risk. Based on a cross-country technique called Data Envelopment Analysis (DEA), an efficiency frontier is constructed to assess if equivalent outcomes could be achieved with less spending. This relative notion of technical efficiency provides a tool to assess how spending could be adjusted across sectors (health versus education) and within sectors (primary versus secondary education). ${ }^{2}$

Improving the efficiency of public expenditure requires overcoming rigidities in budgetary management. This paper considers budget rigidities as factors that limit the discretionary scope to adjust spending in line with shifting policy priorities or macroeconomic circumstances. Budget rigidities in Slovenia include institutional and legal structures such as quasi-autonomous spending that are beyond direct government control (e.g., hospitals and schools), the funding mechanism for social services, the wide coverage of social entitlements and inflexible collective agreements. As most spending becomes flexible over the long run, this paper focuses on factors that limit the fiscal room to maneuver within one to two fiscal years in the absence of a major structural reform or the reopening of collective agreements.

This paper finds that public spending is relatively high in Slovenia without achieving correspondingly better outcomes compared to other new EU member states. Inefficiencies in spending stem from a range of factors, including: (i) the funding mechanism for basic social services; (ii) institutional arrangements; (iii) the broad coverage of publicly provided healthcare services; (iv) weakly targeted social benefits; and (v) inadequate cost recovery in pre-primary and higher education. Moreover, the composition of public spending is heavily tilted towards nondiscretionary items, such as social benefits and employee compensation. This allocation fosters rigidity in spending, which might partially explain the disproportionate burden of fiscal adjustment borne by flexible components of spending, such

\footnotetext{
${ }^{1}$ Potential distortions from restraining capital spending and goods and services include underinvestment in infrastructure, inadequate teaching aids (such as textbooks or computers), and medical supplies.

${ }^{2}$ This approach is analogous to an aggregated form of performance-based budgeting.
} 
as public investment. This paper argues that greater discretionary room to adjust spending is needed to focus medium-term expenditure rationalization on inefficient outlays rather than relying on distortionary cuts in the most flexible expenditure categories.

The remainder of this paper is organized as follows: Section II summarizes key stylized facts to motivate key questions, Section III assesses the relative efficiency of health, education and social protection expenditures; Section IV explores the major sources of budget rigidity in Slovenia and outlines initial steps to enhance flexibility; and Section V concludes.

\section{STYLIZED FACTS AND KEY ISSUES}

The composition and level of public spending in Slovenia compared to other EU countries raises a number of concerns regarding efficiency and budget rigidity. For instance, it is unclear if the ambitious medium-term target to reduce expenditure can be achieved if past approaches to expenditure adjustment continue to be followed. The high level of spending might also reflect inefficiencies that would allow for lower spending without sacrificing outcomes. Finally, the relative stability of spending in Slovenia raises concerns that budget rigidities could hamper future consolidation efforts. This section outlines these questions in the context of the stylized facts on public expenditure.

\section{A. Pattern of Public Expenditure Adjustment ${ }^{3}$}

Slovenia will need to adopt a different pattern of expenditure adjustment compared to previous approaches. For instance, primary spending as a share of GDP was unchanged during 2000-05 as traditionally flexible areas of expenditure were restrained to make room for other spending items (Figure 1). Specifically, cuts in capital transfers and intermediate consumption of 1.4 percent of GDP fully offset higher spending on subsidies, social benefits, and employee compensation, all of which tend to be rigid to short-term expenditure adjustment. Moreover, spending reductions were concentrated in categories that represent a relatively small share of total spending (Figure 2).

High taxes and the small share of flexible spending limit the scope to accommodate emerging spending pressure through higher revenue or expenditure restraint. The tax burden in Slovenia was over 40 percent of GDP in 2005, while total spending was more than 6 percentage points of GDP higher than in the eight New Member States ${ }^{4}$ (NMS-8) and

\footnotetext{
${ }^{3}$ Fiscal data used in this section correspond to the general government sector from Eurostat Government Finance Statistics Template Table. Expenditure ratios are calculated using nominal GDP available from Eurostat. To calculate the sensitivity of spending to economic cycles we use GDP at constant prices from IMF's World Economic Outlook (WEO). The wage share in 2004 of education, health and social protection is available from Eurostat Task Force on COFOG.

${ }^{4}$ NMS- 8 countries include Czech Republic, Estonia, Hungary, Latvia, Lithuania, Poland, Slovak Republic, and Slovenia.
} 
4 percentage points of GDP higher than in the advanced EU-15 countries (Figure 2). Moreover, the relatively small share of traditionally flexible spending limits the scope for rapid expenditure restraint. Section III identifies potential budget rigidities that should be addressed in this regard and outlines initial steps to enhance spending flexibility.

Figure 1. Slovenia: Composition of Expenditure Adjustment, 2000-05 1/ (Change in percentage points of GDP)

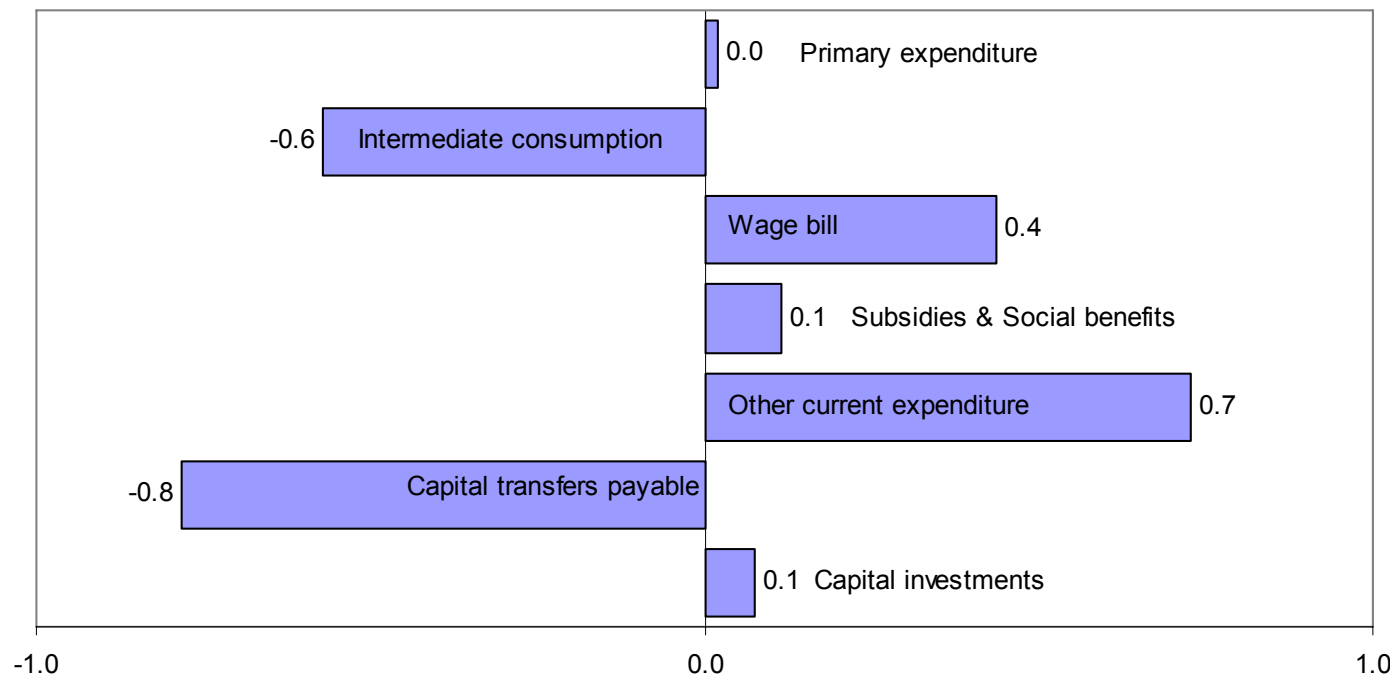

Source: Eurostat

1/ Annual spending trends between 2000 and 2005 are smooth for all components with no outliers.

Figure 2. Average Expenditure by Economic Category, 2000-05 1/ (As a percent of GDP)

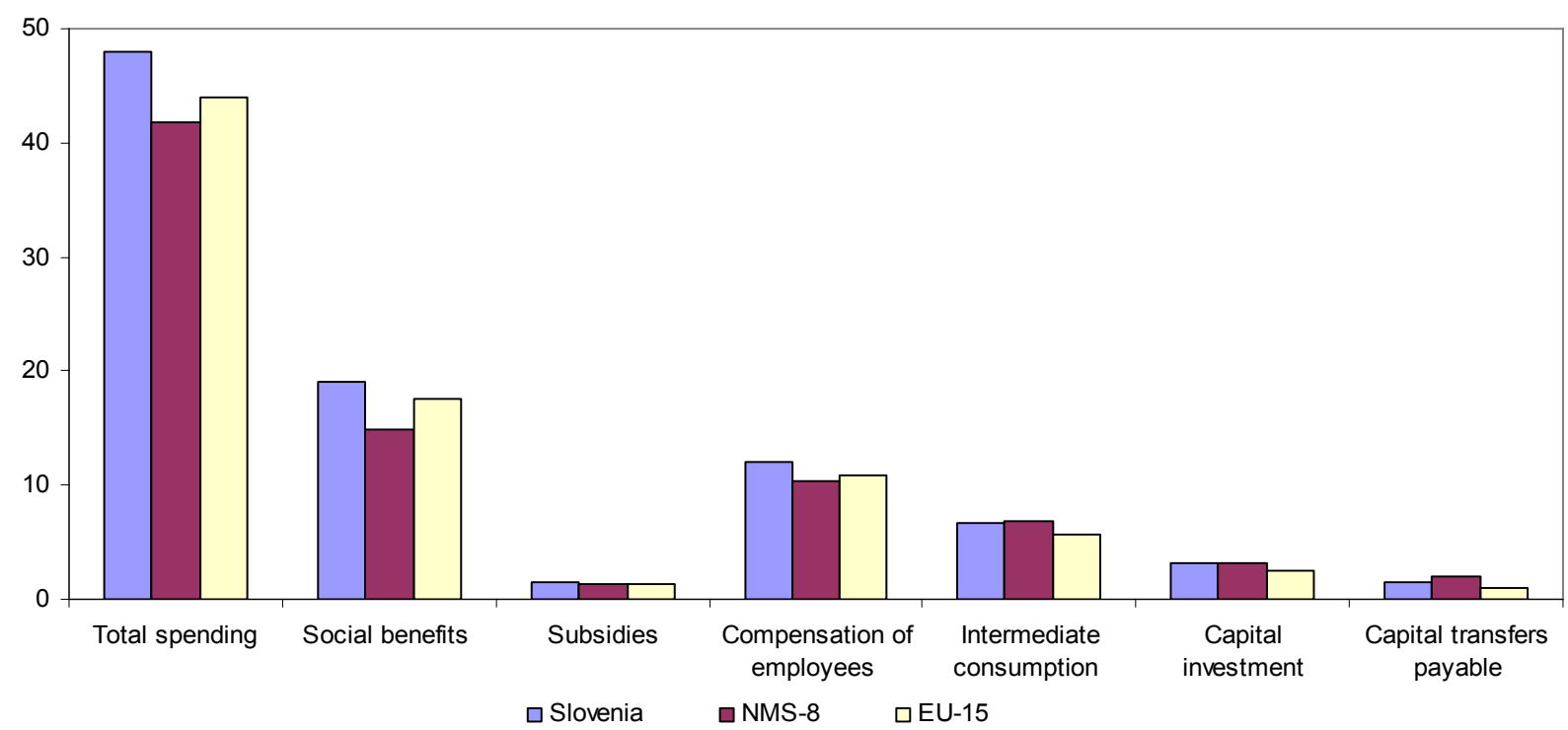

Source: Eurostat

1/ NMS-8 and EU-15 figures for each expenditure component are calculated by taking the average of each country's average expenditure during the $2000-05$ period. 


\section{B. Functional Spending in Slovenia Compared to EU-15 and NMS-8 Countries}

Expenditure in Slovenia is significantly higher than the average of other NMS-8 countries. Specifically, average total spending during 2000-05 amounted to 48 percent of GDP compared to an average of 42 percent of GDP in the NMS- 8 countries. The main drivers of higher spending in Slovenia are mainly rigid social benefits and employee compensation (Figure 2). In addition, spending in major functional categories also appears higher than in other NMS-8 countries. For instance, Figure 3 illustrates that social protection spending was higher in Slovenia than the NMS-8 average by 6.4 percent of GDP in 2004. Health and education spending were higher than the NMS- 8 average by 1.7 and 0.2 percent of GDP, respectively.

Figure 3. Comparison of Major Functional Spending Categories, 2004 (As a percent of GDP)

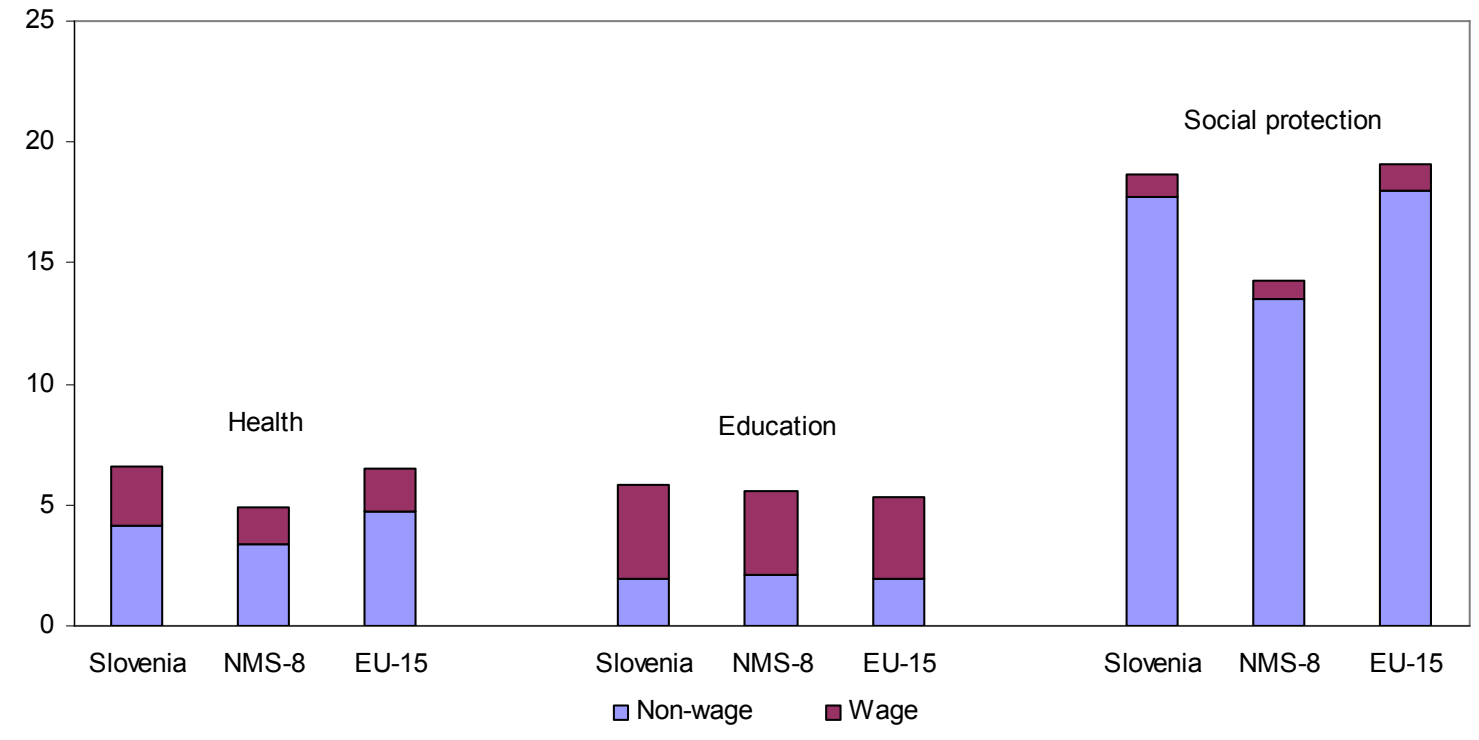

Source: Eurostat

Similarly, the share of employee compensation in health and education spending is relatively large in Slovenia. Figure 3 illustrates that in 2004, employee compensation (a typically rigid area of spending) represented 38 percent of health spending in Slovenia compared to 31 and 28 percent in the NMS-8 and EU-15 countries, respectively. Employee compensation in education also appears relatively high in Slovenia at 67 percent of spending, compared to 63 percent in the NMS- 8 countries. The high level and composition of these functional spending categories point to potential inefficiencies that are the focus of Section D. Specifically, if higher spending has not achieved correspondingly better performance compared to other EU countries, then there might be scope to trim spending without sacrificing outcomes. 


\section{Budget Rigidity in Slovenia}

Spending appears relatively stable in Slovenia compared to other EU countries. For instance, social benefits in the NMS-8 countries exhibit almost twelve times the variation of Slovenia based on the coefficient of variation (Table 1). ${ }^{5}$ Similarly, total expenditure and employee compensation in the NMS-8 countries are over three times as volatile as in Slovenia. Traditionally flexible areas of expenditure also exhibit significantly less variance in Slovenia. This broad pattern highlights potential budget rigidities that might constrain the discretionary scope of policy makers to adjust spending. This will be explored in Section III.

Table 1. Variation in Key Expenditure Categories, 2000-05 (Standard deviation to the mean in percent)

\begin{tabular}{lccc}
\hline & Slovenia & NMS-8 & EU-15 \\
\hline Total spending & 1.2 & 4.0 & 2.6 \\
Intermediate consumption & 4.9 & 6.9 & 5.0 \\
Compensation of employees & 1.6 & 4.9 & 2.9 \\
Subsidies & 7.4 & 19.3 & 7.8 \\
Social benefits & 0.4 & 5.2 & 3.4 \\
Other current expenditure & 12.1 & 40.7 & 8.1 \\
Capital transfers payable & 37.7 & 86.6 & 20.1 \\
Capital investments & 8.1 & 16.0 & $14.51 /$ \\
\hline
\end{tabular}

Sources: Fund staff calculations of standard deviations are based on Eurostat data.

1/ Excludes Germany due to missing data.

The high share of nondiscretionary spending also points to potential budget rigidities. Nondiscretionary spending includes rigid areas of expenditure owing to collective agreements, legislation governing social entitlements, subsidies and interest. ${ }^{6}$ The relatively large share of nondiscretionary spending in Slovenia, at 72 percent of total spending, stems largely from generous social benefits (Figure 4). This compares with nondiscretionary spending in the NMS-8 countries of 68 percent of total spending on average. Section $\mathrm{C}$ explores factors underlying the relative stability of spending in Slovenia, including budget rigidities.

\footnotetext{
${ }^{5}$ The pattern of results in Table 1 is robust to detrended expenditure data using the Hodrick-Prescott filter.

${ }^{6}$ Nondiscretionary spending is defined as social benefits, interest, compensation to employees, and subsidies.
} 


\section{Figure 4: Discretionary and Nondiscretionary Share of Expenditure (As a percent of total spending)}

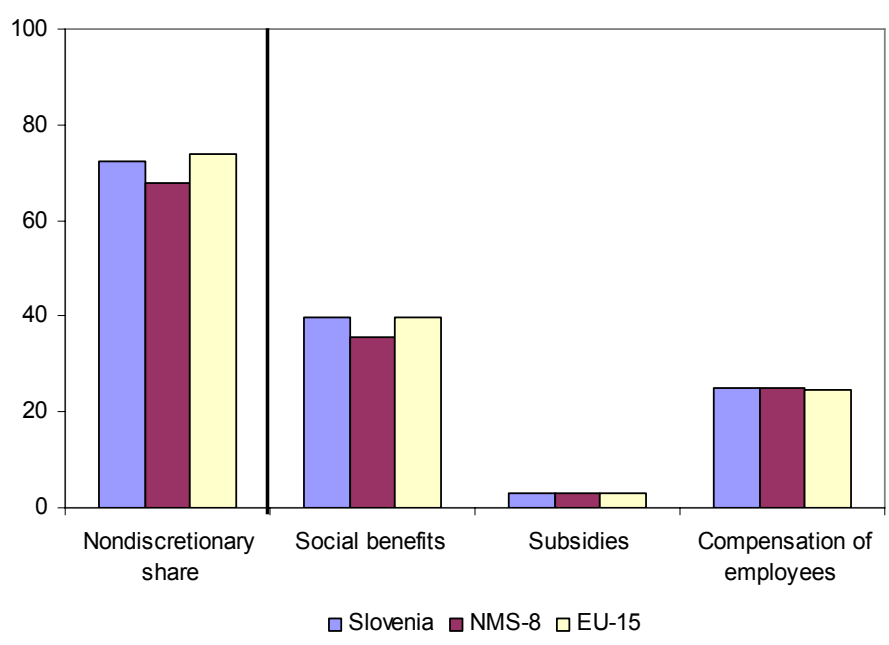

Sources: Fund staff calculations of spending shares are based on Eurostat data.

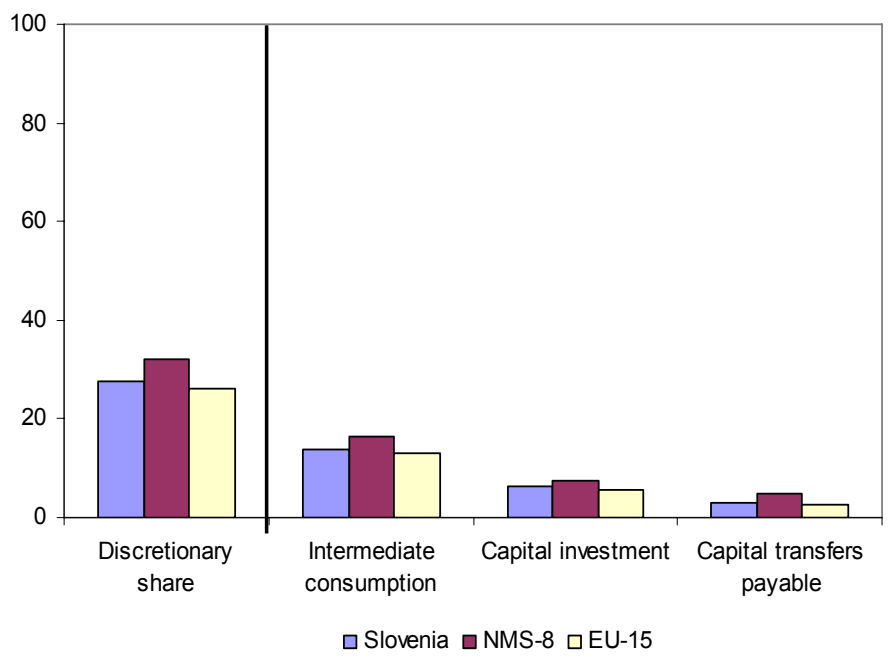

Sources: Fund staff calculations of spending shares are based on Eurostat data.

\section{ASSESSING EFFICIENCY AS A BENCHMARK TO GUIDE EXPENDITURE RATIONALIZATION}

The effectiveness of expenditure rationalization can be strengthened by focusing cuts in relatively inefficient areas of spending so that social outcomes can be largely insulated from the fiscal adjustment. In this context, the efficiency of public spending depends on maintaining sufficient budgetary flexibility so that the expenditure rationalization can better target inefficient spending. Social expenditures in Slovenia are on par with the level of expenditure in the EU-15 countries (Figure 3) while a large share of expenditures is nondiscretionary and potentially rigid to adjustment (Figure 4). This section explores the performance of high social expenditures in Slovenia compared to EU-15 and other NMS-8 countries. We measure expenditure efficiency in Slovenia for health, education and social expenditures and benchmark the relationship between expenditures in these sectors and outcomes across a sample of comparable countries. ${ }^{7}$

\footnotetext{
${ }^{7}$ Data on health and social protection transfers are drawn from the IMF Government Finance Statistics 2001 database. Eurostat provides data by economic classification while the IMF database provides data by functional classification. Education spending data is obtained from the UNESCO Institute for Statistics. Outcome indicators in the health, education and social protection areas are drawn from a variety of sources. Health outcome measures are obtained from the World Health Organization's Core Health Indicators and World Health Statistics 2005. The at-risk-of-poverty measures are taken from Eurostat's Population and Social Conditions. Primary and tertiary education outcomes are drawn from UNESCO while for secondary education we use the Trends in International Mathematics and Science Study (TIMSS) mathematics test scores. Table A1 summarizes the coverage of countries and time periods of key input and output/outcome data.
} 


\section{A. Methodology}

Efficiency is assessed using a cross-country approach that measures the effectiveness of spending in producing outcomes. The relative efficiency of spending inputs and outcomes in each country is assessed using the Data Envelope Analysis (DEA) technique developed by Farrell (1957) and popularized by Charnes, Cooper, and Rhodes (1978). Based on the assumption of a convex production possibilities set, a piecewise linear "efficiency frontier" is constructed as the linear combination of efficient input and output combinations in the crosscountry sample. Figure 5 illustrates an efficiency frontier that connects points A to D as these countries dominate other input-output pairs, such as countries E and $\mathrm{G}$ in the interior. The convexity assumption allows an inefficient input-output pair such as point $E$ to be assessed relative to a hypothetical position on the efficient frontier such as point $Z$ by taking a linear combination of efficient country pairs, such as points A and B. In this manner, an input-based technical efficiency score that is bounded between zero and one can be calculated as the ratio of YZ to YE. The score corresponds to the proportional reduction in spending consistent with relatively efficient production of a given outcome. ${ }^{8}$ Similarly, an output-based technical efficiency score for point $\mathrm{E}$ can be calculated as the ratio of XF to XE, consistent with the proportional increase in the outcome indicator given current spending if production is relatively efficient. This would correspond to the hypothetical point $\mathrm{F}$ that is calculated as a linear combination of the actual countries $\mathrm{B}$ and $\mathrm{C}$. This paper limits its focus to input-based efficiency in line with the policy focus on medium-term expenditure rationalization. ${ }^{9}$

\section{Figure 5. DEA Single Input and Output Diagram}

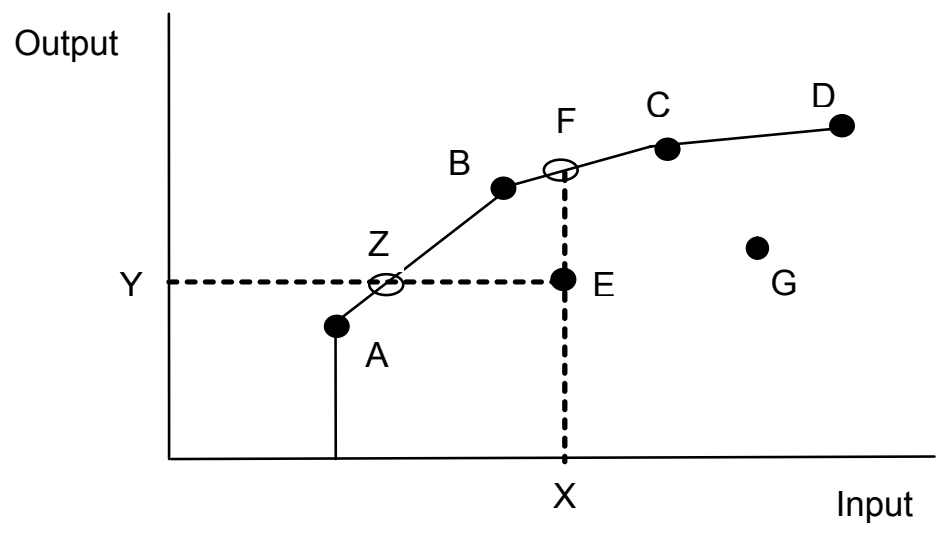

Although DEA avoids econometric pitfalls in assessing expenditure efficiency, the technique also involves important caveats. DEA is a powerful tool to assess spending efficiency as it

\footnotetext{
${ }^{8}$ In practice, many factors affect the link between public spending and performance. Simar and Wilson (2007) outline a second stage bootstrapping procedure to control for these factors.

${ }^{9}$ The input- and output-based efficiency scores are equal assuming constant returns to scale. The DEA models in this paper permit variable returns to scale given the sharp decrease in outcomes at higher spending levels. See Zhu (2003) for a detailed technical treatment of the DEA approach.
} 
does not require an assumption about unknown functional forms or complex distributional properties. However, as a relative measure of efficiency, DEA is highly sensitive to sample selection and measurement error. As a result, outliers can exert a large effect on the efficiency scores and shape of the frontier. For this reason, proper sample selection is critical to ensure that cross-country input-output bundles are comparable. Also, because the methodology focuses on inputs and outputs that can be quantified, it may overlook important factors that are harder to measure, such as quality. In addition, it is important to ensure that spending inputs are compared with outcomes that are actually targeted by policymakers. Further, many public policy targets are impacted by private spending. As a result, large differences across countries in private health or education spending could bias efficiency scores. This paper focuses on public spending as an initial step toward assessing spending efficiency. In addition, exogenous factors beyond direct government control should be considered when interpreting efficiency scores, such as variation in initial conditions. ${ }^{10}$

The literature on DEA and related techniques is well-developed. Gupta and Verhoeven (2001) adopted an efficiency frontier approach to assess education spending in 37 African countries during 1984-95. They found evidence of significant inefficiencies in African countries compared to Asian and Western Hemisphere countries, suggesting the need for greater efficiency rather than higher spending. Afonso and St. Aubyn (2004) assessed the efficiency of education and health spending in OECD countries using both DEA and a related technique. They found that countries with low public spending tend to have better outcomes than higher-spending countries. Herrera and Pang (2005) evaluated spending in 140 countries using DEA technique and found that (i) high-spending countries appear less efficient; (ii) countries with a relatively large wage bill perform less efficiently; and (iii) countries with higher aid dependency achieve lower efficiency results. Finally, Afonso and others (2006) applied DEA to assess the efficiency of public spending in a sample of emerging market and EU countries. A novel feature of their work was the use of Tobit regressions to control for exogenous factors affecting efficiency results that are beyond government control based on procedures developed by Simar and Wilson (2007).

\section{B. Relative Efficiency of Public Health Spending in Slovenia}

\section{Child and maternal mortality}

The efficiency of public health spending is sensitive to the level of government coverage and sample selection. Based on consolidated central government data, health spending attains the efficient frontier in terms of reducing child mortality compared to other EU countries. ${ }^{11}$

\footnotetext{
${ }^{10}$ For instance, differences in geography could affect the efficiency of motorway investment, as a mountainous country could spend more per kilometer while still operating efficiently. Similarly, countries with higher initial GDP per capita levels tend to have better technology and stronger initial education and health outcomes.

${ }^{11}$ In principle, the health spending input should be directly related to the performance indicator. For example, health spending on reducing child mortality should be linked to results in reducing child mortality rates. However, such disaggregated data on health spending are not available for most countries in the sample.
} 
However, Slovenia appears less efficient based on general government data and a broader sample of countries (Figure 6). In this scenario, Slovenia ranks $18^{\text {th }}$ out of 26 countries with an efficiency score of 0.68 ; this implies that expenditure could be 32 percent lower and achieve an equivalent outcome. However, efficiency scores should be interpreted cautiously. This analysis assumes that reducing the child mortality rate is an explicit goal of health spending. Moreover, reducing overall health spending would affect other health outcomes as well. The efficiency frontier also exhibits sharply decreasing returns to scale once health spending exceeds about 5 percent of GDP, suggesting that marginal resources could be reallocated to other areas which would generate a larger impact.

Figure 6. Efficiency of Public Spending in Reducing Child Mortality

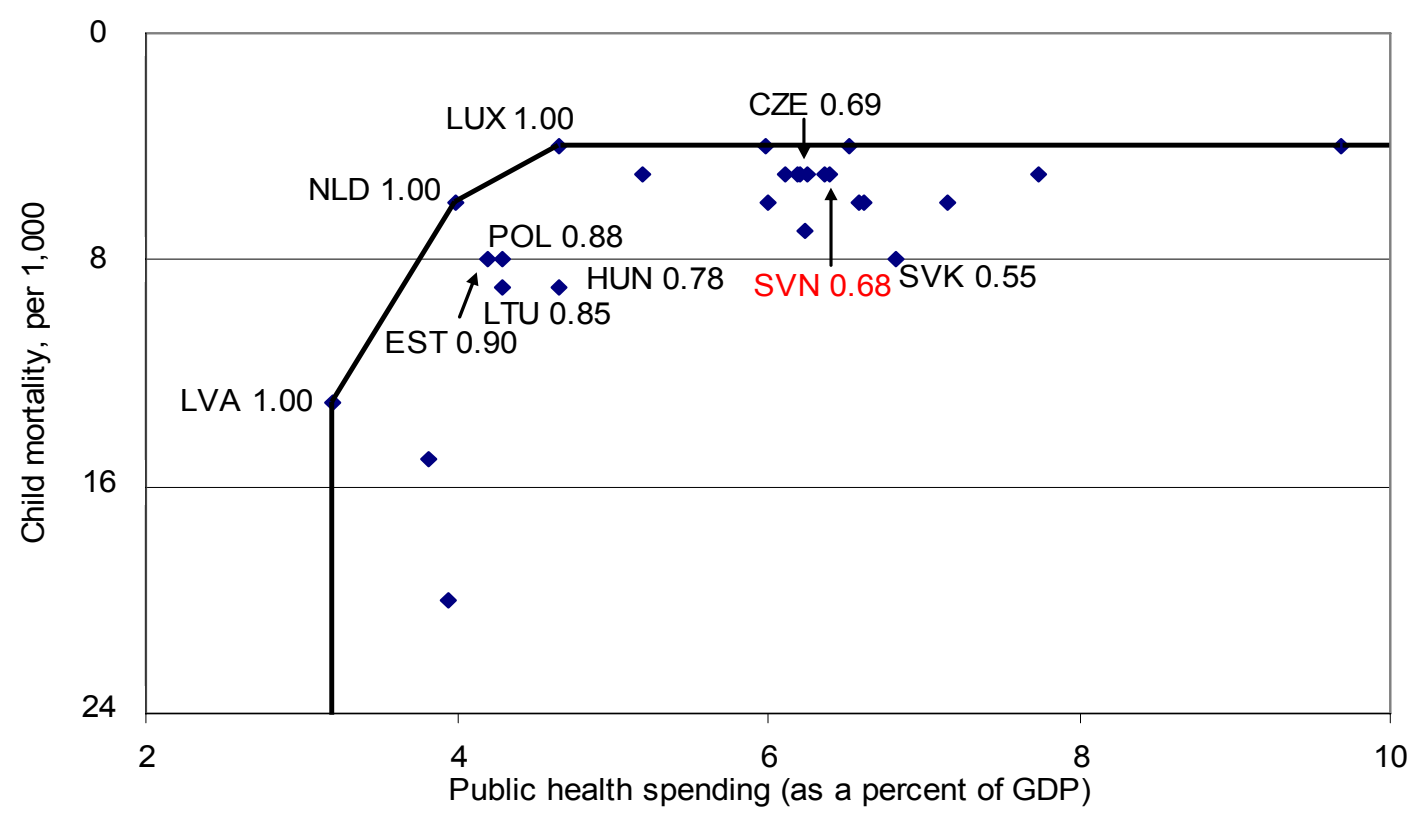

Sources: WHO for child mortality statistics; Eurostat for data on spending and GDP.

Maternal mortality rates are relatively high in Slovenia given the level of public health spending. The average maternal mortality rate in the EU-15 countries is 42 percent lower than in Slovenia even though public health spending is comparable, at 6.3 to 6.4 percent of GDP. Although maternal mortality in Slovenia is 20 percent lower than the NMS- 8 average, average public health spending is higher by almost 30 percent. Consequently, Slovenia's efficiency score is 0.62 , ranking it $24^{\text {th }}$ out of 26 countries in the sample. These results raise major concerns regarding the effectiveness of relatively high health care spending. However, one problem with this indicator is that a single outlier in a small country like Slovenia could significantly affect the mortality rate. ${ }^{12}$

\footnotetext{
${ }^{12}$ The maternal mortality rate is measured per 100,000 births. There are only about 18,000 births each year in Slovenia. As a result, a single outlier could result in sharp swings.
} 


\section{Standardized death rates (SDRs)}

Based on a range of SDRs from different causes, Slovenia also appears relatively inefficient compared to NMS-8 and EU-15 countries. For example, Slovenia ranks $19^{\text {th }}$ out of 25 countries in the sample in efficiency at reducing the SDR from all causes, with an efficiency score of 0.6. This result reflects the fact that the SDR from all causes is about 15 percent higher in Slovenia compared to the EU-15 average, while health spending is comparable as a share of GDP. Moreover, the SDRs in Slovenia from circulatory and digestive disorders are 20 and 80 percent higher than in the EU-15, respectively. Although SDR from all causes is 20 percent lower in Slovenia than the NMS-8 average, public health spending is about one-third higher. These results suggest either that lower health spending in Slovenia could potentially achieve comparable outcomes, or that current spending could potentially achieve better outcomes.

\section{Multiple outcome health model}

Public health spending appears particularly inefficient through the lens of a multiple outcome model. Table 2 demonstrates that Slovenia ranks $18^{\text {th }}$ out of 22 countries in a multiple outcome model including child and maternal mortality rates, the SDR from all causes, and years of healthy life expectancy. Nine countries were identified as relatively efficient in the sample, reflecting in part the nature of the multiple outcome approach that ranks countries as efficient if they perform strongly in at least one outcome. The results in Table 2 also demonstrate that both low-spending and low-outcome countries (Latvia and Poland) and high-spending and high-outcome countries (Sweden and Italy) are relatively efficient. These results suggest that outcomes could be strengthened in Slovenia or that spending could be significantly reduced while remaining consistent with current outcome indicators. 
Table 2. Multiple Outcome Health Sector Efficiency Model

\begin{tabular}{lccccccc}
\hline & $\begin{array}{c}\text { Maternal } \\
\text { mortality } \\
\text { (per }\end{array}$ & $\begin{array}{c}\text { Child } \\
\text { mortality } \\
\text { (per 1,000) }\end{array}$ & $\begin{array}{c}\text { Healthy life } \\
\text { expectancy } \\
\text { (years) }\end{array}$ & $\begin{array}{c}\text { SDR: all } \\
\text { causes } \\
\text { (per 100,000) }\end{array}$ & $\begin{array}{c}\text { Health } \\
\text { spending } \\
\text { (percent } \\
\text { of GDP) }\end{array}$ & $\begin{array}{l}\text { Efficiency } \\
\text { Score }\end{array}$ & Rank \\
\hline Latvia & 61 & 13 & 60.9 & 1113.6 & 3.2 & 1.00 & 1 \\
Netherlands & 16 & 6 & 70.3 & 666.2 & 4.0 & 1.00 & 1 \\
Poland & 10 & 8 & 64.8 & 891.5 & 4.3 & 1.00 & 1 \\
Luxembourg & 28 & 4 & 70.8 & 706.4 & 4.7 & 1.00 & 1 \\
Spain & 5 & 5 & 71.4 & 600.1 & 5.2 & 1.00 & 1 \\
Finland & 5 & 4 & 70.4 & 660.1 & 6.0 & 1.00 & 1 \\
Ireland & 4 & 6 & 69.3 & 721.3 & 6.0 & 1.00 & 1 \\
Italy & 5 & 5 & 71.6 & 576.3 & 6.1 & 1.00 & 1 \\
Sweden & 8 & 4 & 72.3 & 598.5 & 6.5 & 1.00 & 1 \\
Lithuania & 19 & 9 & 61.8 & 1008.3 & 4.3 & 0.92 & 10 \\
Hungary & 11 & 9 & 62.8 & 1048.0 & 4.7 & 0.91 & 11 \\
Estonia & 38 & 8 & 62.7 & 1090.6 & 4.2 & 0.90 & 12 \\
Germany & 9 & 5 & 70.7 & 665.2 & 6.2 & 0.81 & 13 \\
Denmark & 7 & 5 & 69.9 & 749.1 & 6.4 & 0.80 & 14 \\
Czech Republic & 9 & 5 & 67.1 & 899.6 & 6.3 & 0.80 & 15 \\
Austria & 5 & 6 & 71.0 & 652.3 & 7.2 & 0.73 & 16 \\
Portugal & 8 & 6 & 67.6 & 727.1 & 6.6 & 0.72 & 17 \\
Slovenia & $\mathbf{5}$ & $\mathbf{5}$ & $\mathbf{6 8 . 2}$ & $\mathbf{7 5 9 . 5}$ & $\mathbf{6 . 4}$ & $\mathbf{0 . 7 2}$ & $\mathbf{1 8}$ \\
France & 17 & 5 & 71.5 & 605.5 & 7.7 & 0.68 & 19 \\
United Kingdom & 11 & 6 & 69.8 & 675.7 & 6.6 & 0.68 & 20 \\
Norway & 10 & 4.0 & 71.1 & 608.2 & 9.7 & 0.66 & 21 \\
Slovak Republic & 10 & 8 & 64.8 & 971.5 & 6.8 & 0.63 & 22 \\
\hline
\end{tabular}

Sources: World Health Organization and Eurostat data; Fund staff estimates of efficiency scores.

\section{Enhancing health sector efficiency}

Health care efficiency could be strengthened by extending a number of existing initiatives. For instance, monitoring of quality and safety of hospital service delivery could be extended by gradually linking performance to the budget process. In addition, initiatives to reform the compensation mechanism for primary health and hospital services should continue to shift operational risk to providers as an incentive to economize resources. For instance, the Diagnosis-Related Groups (DRG) system for hospital financing involves collectively negotiated compensation rates for over 600 diagnoses based on the expected cost of service delivery rather than the actual cost. Similarly, the capitation rule for compensating primary health care providers is based on the expected cost of service delivery. Performance indicators suggest implementation of the DRG system has coincided with a decline in the average duration of hospital admission and a lower number of inappropriate admissions. Ensuring that hospitals properly input and code diagnoses in the DRG system could yield additional efficiency savings. Other reform initiatives should continue to be actively pursued, such as establishing reference price lists for "mutually interchangeable" drugs to save up to an estimated 10 percent of drug costs and centralizing pharmaceutical and medical equipment procurement to benefit from bulk buying to save an estimated 10 to 30 percent. Finally, 
expanding private concessions from local governments of primary health facilities can provide an opportunity to enhance competition among providers and lower costs. However, the design of concessions should be cautious, ensuring that fees are sufficient to cover capital and depreciation costs and avoiding contingent liabilities for government.

Additional measures to restructure the health care financing system could also generate efficiency savings. Specifically, the system of compulsory public insurance by the Health Insurance Institute of Slovenia (HIIS) and the voluntary health insurers (VHIs) should be carefully reviewed. Compulsory social contributions to the HIIS are allocated towards the cost of providing a broad basket of health care services. Co-payments ranging from 15 to 95 percent of the cost of services are covered by the VHIs. As over 90 percent of the population is covered by voluntary co-payment insurance, co-payments have not been effective in rationalizing demand. Moreover, the private insurance system acts effectively as an arm of the compulsory HIIS, since it also sets premiums based on earnings. Future reforms to enhance health sector efficiency should include reviewing the broad coverage of basic benefits covered by the HIIS and reorienting the coverage of voluntary health insurance from co-payments to excluded services from the publicly provided basket, tertiary services, dental care and pharmaceuticals. In this manner, out-of-pocket co-payments will better rationalize excess demand. Moreover, VHIs should be permitted to establish insurance premiums based on risk attributes to strengthen efficiency (Tajnikar and Bonča, 2005). ${ }^{13}$

\section{Relative Efficiency of Public Education Spending}

\section{Primary education}

Primary education spending appears particularly inefficient in Slovenia. Slovenia spent about $2 \frac{1}{2}$ times more than the NMS- 8 countries on average based on UNESCO data for primary education spending per student as a share of GDP per capita during 1998-2002. Part of this higher spending could reflect the inclusion of preprimary child care costs that might not be included in other country data. In addition, high primary school spending in Slovenia reflects an excess number of primary school teachers and facilities. These numbers have not kept pace with the declining primary school-age population, resulting in high overhead costs. However, Figure 7 suggests that a high rate of employee compensation or non-wage spending could also be an issue as the primary student-teacher ratio is comparable to other

\footnotetext{
${ }^{13}$ As the cost of voluntary health insurance for co-payments currently depends only on earnings rather than risk characteristics such as age and lifestyle, the private system is comparable to charging a higher social contribution rate through the compulsory insurance system. This was also a conclusion of the 2003 white paper on health care reform. Private insurers also face moral hazard, adverse selection and higher administrative costs compared to the mandatory insurance fund. This explains the need for a complex risk-adjustment mechanism that compensates private insurers for the risk attributes of their customers. For instance, the current rate structure pools risk so that younger workers subsidize older beneficiaries. However, companies with younger customers on average earn greater profits under this pooled-risk system, which requires compensating transfers between insurance companies.
} 
countries in the sample despite significantly higher expenditure in Slovenia. ${ }^{14}$ In this context, Slovenia ranks $42^{\text {nd }}$ out of 45 countries with an efficiency score of 0.21 , indicating that the relatively high level of primary education spending has not produced a significantly lower student-teacher ratio.

Figure 7. Efficiency of Primary Education in Lowering the Student-Teacher Ratio

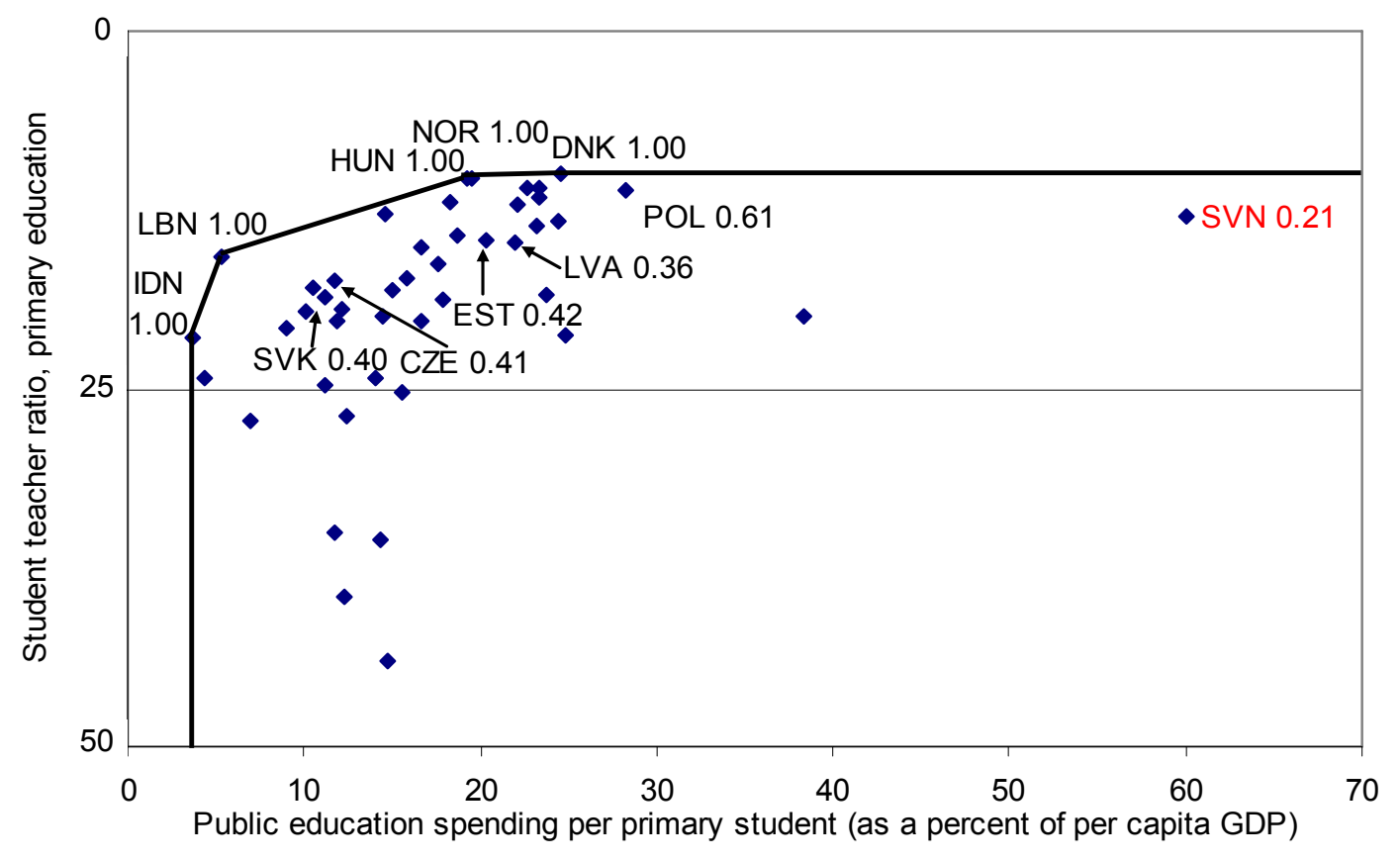

Source: Spending per student as a share of GDP and student-teacher ratio from UNESCO.

\section{Secondary and tertiary education}

Secondary education also appears relatively inefficient in terms of international standardized test scores. Slovenia achieved an average score on the TIMSS ${ }^{15}$ standardized test in mathematics about 26 points lower than the average for the five NMS- 8 countries with available test score data. ${ }^{16}$ On the same token, Slovenia spends almost 40 percent less than these same countries in terms of secondary school spending per pupil as a share of GDP per capita. Secondary schools fall more directly under central government control compared to locally established primary schools, which might partly explain why secondary school

\footnotetext{
${ }^{14}$ The pupil-teacher ratio is a proxy for an outcome indicator, such as quality or effectiveness of primary education.

15 Based on the U.S. Department of Education's Trends in Mathematics and Science Study (TIMSS).

16 The NMS-8 countries with available TIMSS scores include Estonia, Hungary, Latvia and the Slovak Republic.
} 
funding per pupil is just 20 percent of that for primary education. The model generated an efficiency score of 0.46 for Slovenia, which ranks $10^{\text {th }}$ out of 19 countries in the sample.

Slovenia ranks better in producing university graduates. Slovenia registered an efficiency score of 0.58 and ranked $13^{\text {th }}$ out of 44 countries in the sample based on its effectiveness in increasing the proportion of graduates as a share of the school-age population. Compared to the NMS-8 countries in the sample, the proportion of university graduates in the school-age population is about 10 percent higher in Slovenia. Tertiary education spending per pupil as a share of GDP per capita is just 4 percent higher.

\section{Multiple outcome education model}

The efficiency of education spending in Slovenia remains weak in a multiple outcome model. The model assessed the efficiency of average public spending as a share of GDP in achieving high primary pupil-teacher ratios, secondary school enrollment rates, and proportions of university graduates relative to the school-age population. Slovenia ranks $22^{\text {nd }}$ out of 23 countries with an efficiency score of 0.69 (Table 3).

\section{Enhancing education sector efficiency}

Slovenia could pursue a number of initiatives to enhance efficiency in the education sector. The monitoring of key outcome indicators should be formalized and gradually linked to the budget process. As a pilot for the implementation of performance-based budgeting, spending at the individual school level could be increasingly linked to outcome indicators. ${ }^{17}$ This process would build on existing work to monitor selected outcome indicators, such as the graduation and dropout rate by level of education, pupil-teacher ratio, academic results and scores on international standardized tests. A key measure for primary education would be to trim the number of primary teachers through natural attrition and implement a selective hiring freeze for new teachers. Plans to merge small primary schools over the coming years are another welcome step. The funding mechanism for primary and secondary schools should also shift increasingly to a per capita-based formula linked to the expected cost of service delivery to encourage more efficient use of budgeted resources. ${ }^{18}$ As the primary and secondary school-age populations are expected to decline over the medium term, schools should also consider pooling resources by jointly hiring and sharing new teachers. In addition, greater cost recovery of preprimary child care costs and university tuition should be pursued. Scholarships should also be targeted to lower-income students to insulate them from the impact of higher tuitions.

\footnotetext{
${ }^{17}$ With about 900 schools, educational facilities represent about half of all public sector institutions.

${ }^{18}$ Secondary schools are more advanced in this direction, as they are more firmly under central government control.
} 
Table 3. Multiple Outcome Education Efficiency Model

\begin{tabular}{lcccccc}
\hline & $\begin{array}{c}\text { Primary } \\
\text { student- } \\
\text { teacher } \\
\text { ratio }\end{array}$ & $\begin{array}{c}\text { Secondary } \\
\text { enrollment } \\
\text { (percent) }\end{array}$ & $\begin{array}{c}\text { Tertiary } \\
\text { total } \\
\text { graduates } \\
\text { (percent) }\end{array}$ & $\begin{array}{c}\text { Public } \\
\text { education } \\
\text { spending } \\
\text { (percent of } \\
\text { GDP) }\end{array}$ & $\begin{array}{c}\text { Efficiency } \\
\text { Score }\end{array}$ & Rank \\
\hline Hungary & 10.4 & 94.9 & 7.3 & 5.89 & 1.00 & 1 \\
Italy & 10.9 & 76.7 & 5.8 & 5.02 & 1.00 & 1 \\
Sweden & 11.6 & 104.1 & 8.5 & 6.86 & 1.00 & 1 \\
Spain & 14.4 & 98.3 & 8.8 & 4.24 & 1.00 & 1 \\
Poland & 11.2 & 63.7 & 12.5 & 5.58 & 1.00 & 1 \\
Ireland & 20.3 & 105.2 & 13.0 & 4.2 & 1.00 & 1 \\
Bulgaria & 17.3 & 68.1 & 7.8 & 3.87 & 1.00 & 1 \\
United Kingdom & 18.0 & 81.4 & 15.3 & 5.19 & 1.00 & 1 \\
Denmark & 10.0 & 93.2 & 11.5 & 8.05 & 1.00 & 1 \\
Germany & 15.1 & 78.5 & 6.7 & 4.3 & 0.96 & 10 \\
Slovakia & 18.7 & 59.6 & 5.5 & 4.04 & 0.96 & 11 \\
Norway & 10.3 & 75.8 & 11.0 & 7.68 & 0.95 & 12 \\
Czech & 17.4 & 57.2 & 4.9 & 4.11 & 0.94 & 13 \\
Romania & 17.9 & 59.3 & 4.6 & 4.15 & 0.93 & 14 \\
Croatia & 18.4 & 56.4 & 4.8 & 4.48 & 0.86 & 15 \\
Portugal & 12.1 & 97.6 & 8.5 & 6.97 & 0.81 & 16 \\
Austria & 13.3 & 63.7 & 5.8 & 5.69 & 0.79 & 17 \\
France & 18.7 & 81.4 & 13.4 & 6.12 & 0.75 & 18 \\
Latvia & 14.7 & 79.0 & 10.9 & 6.3 & 0.74 & 19 \\
Finland & 16.2 & 82.8 & 11.6 & 6.44 & 0.71 & 20 \\
Belgium & 12.0 & 66.1 & 10.0 & 7.24 & 0.70 & 21 \\
Slovenia & 13.0 & $\mathbf{6 3 . 1}$ & $\mathbf{8 . 5}$ & $\mathbf{6 . 6 8}$ & $\mathbf{0 . 6 9}$ & $\mathbf{2 2}$ \\
Estonia & 14.5 & 79.8 & 8.1 & 7.2 & 0.59 & 23 \\
\hline
\end{tabular}

Sources: UNESCO and Eurostat data; Fund staff estimates of efficiency scores

\section{Relative Efficiency of Social Protection Transfers}

\section{Poverty risk}

Although social protection transfers are relatively large in Slovenia, the additional spending has not resulted in a significantly lower risk of poverty after transfers. In a sample of 26 countries, Slovenia ranked $19^{\text {th }}$ in terms of the efficiency of social protection outlays in reducing the proportion of the population at risk of slipping into poverty. ${ }^{19}$ This may reflect a relatively more equalitarian earnings structure in Slovenia before transfers. Consequently, the

\footnotetext{
${ }^{19}$ The outcome indicator is calculated as the percentage point difference in the proportion of the population at risk of poverty before and after social protection transfers. An alternative approach would be to use the percent reduction in the ratio of the population at risk of poverty before and after transfers. However, this would treat a decline from 10 to 5 percent of the population equivalently to a decline from 30 to 15 percent. In the Slovenian context, the rate of poverty risk before transfers is almost the lowest in the sample while the level of social spending is relatively high, which motivates our focus on the percentage point reduction in poverty risk.
} 
high level of social benefits might be less effective due to decreasing returns to scale in reducing poverty risk compared to economies with greater earnings dispersion before transfers. This inefficiency imposes a potentially large fiscal burden, as social protection transfers were over 18 percent of GDP during 2002-03 compared to the sample average of 16.7 percent of GDP. While high-spending countries generally ranked poorly, Denmark reached the efficiency frontier despite social protection spending of more than 20 percent of GDP, as it successfully lowered poverty risk by almost 20 percentage points (more than any other country in the sample). This suggests that there is substantial scope to better target social spending in Slovenia to improve outcomes.

\section{Effectiveness of targeting social benefits}

The wide coverage of social benefits in Slovenia is not well targeted to low-income households. The 2002 household budget survey provides information on market income and social protection transfers for a random sample of over 1,100 individuals. ${ }^{20}$ Table 4 demonstrates that the earnings distribution by quintile is largely unaffected by social protection transfers other than pensions (the first quintile in the table corresponds to the lowest-income quintile). As a result, the efficiency of nonpension social benefits in reducing earnings inequality could be strengthened by trimming benefits to upper-income households and redirecting the savings to low-income households. For instance, the top income quintile (denoted fifth quintile) receives 16 percent of total nonpension social benefits, which does little to address social outcomes such as lowering poverty risk. Improved targeting of nonpension social benefits could reduce overall spending while improving outcome indicators.

\section{Table 4. Impact of Social Benefits in Reducing Earnings Inequality (In tolars, unless otherwise indicated)}

\begin{tabular}{lccccc}
\hline & Income, Pensions, Other Receipts & \multicolumn{3}{c}{ After Social Transfers } \\
\cline { 2 - 6 } & $\begin{array}{c}\text { Average } \\
\text { income in } \\
\text { quintile }\end{array}$ & $\begin{array}{c}\text { Share of total } \\
\text { earnings in } \\
\text { sample } \\
\text { (percent) }\end{array}$ & $\begin{array}{c}\text { Average } \\
\text { income in } \\
\text { quintile }\end{array}$ & $\begin{array}{c}\text { Share of } \\
\text { total } \\
\text { transfers } \\
\text { percent) }\end{array}$ & $\begin{array}{c}\text { Share of total } \\
\text { earnings in } \\
\text { sample } \\
\text { (percent) }\end{array}$ \\
\hline First quintile & $1,135,256$ & 7 & $1,376,294$ & 23 & 7 \\
Second quintile & $2,315,159$ & 13 & $2,584,891$ & 26 & 14 \\
Third quintile & $3,200,545$ & 18 & $3,410,876$ & 20 & 18 \\
Fourth quintile & $4,240,799$ & 24 & $4,384,495$ & 14 & 24 \\
Fifth quintile & $6,546,620$ & 37 & $6,714,641$ & 16 & 35 \\
Overall & $3,484,990$ & 100 & $3,691,588$ & 100 & 100 \\
\hline
\end{tabular}

Sources: Authorities and Fund staff calculations of the earnings distribution by quintile.

\footnotetext{
${ }^{20}$ Income is defined as market earnings, pensions and nongovernment receipts, such as gifts and property sales. Transfers include social and unemployment benefits.
} 


\section{IV.SOURCES OF BUDGET RIGIDITY IN SLOVENIA}

The previous section demonstrated that relatively high social expenditures in Slovenia have not been accompanied by correspondingly strong results in the health, education, and social sectors. Instead, the link between expenditures and outcomes has seemingly been eroded by various inefficiencies. As a result, a targeted rationalization of expenditure in relatively inefficient areas could reduce spending without necessarily affecting social outcomes. Nonetheless, limited spending flexibility could reflect rigidities in budgetary management that risk hampering the rationalization of inefficient expenditure items.

The stylized facts outlined in Section II depict a highly stable pattern of spending (Table 1) and a relatively high share of nondiscretionary spending (Figure 4). Although the optimal degree of spending flexibility is unclear, additional flexibility appears warranted in Slovenia to help achieve the envisaged expenditure rationalization over the medium term. This section adopts different approaches to explain inflexible spending in Slovenia. As a first step, section A explores the cyclical sensitivity of spending to the output gap to assess if spending stability simply reflects a moderate business cycle. As cyclical factors appears insufficient to explain the stability of spending, section B identifies rigidities arising from institutions, financing mechanisms, social protection, and employee compensation. Section C outlines initial steps to enhance flexibility.

There is growing interest among policymakers in tackling rigid budget structures that limit the discretionary scope to adjust expenditure. Despite its importance in operational work, there has been surprisingly little focus on this problem in the literature. However, Alier (2006) recently found in a sample of Latin American countries that revenue earmarking is particularly problematic in reducing the discretionary scope to adjust spending. His analysis is based on the share of nondiscretionary spending and the subset of spending that is financed by earmarked revenue. While earmarking is less prevalent among NMS-8 countries, other forms of budget rigidity are important, as discussed below in the subsection on budget rigidities.

\section{A. Cyclical Variation in Spending}

Output gaps have been relatively stable in Slovenia compared to other EU countries, contributing to reduced cyclical variation in spending. However, the cyclical responsiveness of spending in Slovenia also appears relatively weak compared to the NMS-8 average, given the low ratio between the volatility of primary spending and the output gap (Table 5). ${ }^{21}$

\footnotetext{
${ }^{21}$ The output gap is measured using the Hodrick-Prescott (1997) filter on logged real GDP. This approach is consistent with the EC methodology until 2002 and Schadler and others (2005). The HP filter is also applied to primary spending as a percent of GDP to remove stochastic trends that would bias the results in Table 2 . Regression analysis would be unreliable in estimating the relationship between primary spending and the output gap, given the limited number of time-series observations for most NMS-8 countries (11 or fewer) and significant structural shifts during the 1990s that could lead to spurious results in small regression models.
} 
Specifically, the relative volatility ratio in Slovenia was less than half the NMS-8 average, suggesting that primary spending might not be highly responsive to fluctuations in the output gap. Other authors have argued that automatic stabilizers play a modest role in NMS-8 countries generally (Schadler and others, 2005), implying that cyclical factors are not the key determinants in understanding spending variation. ${ }^{22}$

Table 5. Variation in Primary Spending and the Output Gap, 2000-05 (Standard deviation of Hodrick-Prescott filtered data)

\begin{tabular}{lccc}
\hline & $\begin{array}{c}\text { Primary spending } \\
\text { (percent of GDP) }\end{array}$ & $\begin{array}{c}\text { Output gap } \\
\text { (percent of potential) }\end{array}$ & Relative volatility \\
\hline NMS-8 average & 2.4 & 0.9 & 2.7 \\
EU-15 average & 1.7 & 0.9 & 1.9 \\
Slovenia & $\mathbf{0 . 6}$ & $\mathbf{0 . 6}$ & 1.2 \\
percent of NMS-8 & 27 & 63 & 43 \\
percent of EU-15 & 39 & 66 & 59
\end{tabular}

Simulation: Setting output gap volatility equal to the NMS-8 average

\begin{tabular}{lccc} 
Slovenia & $\mathbf{1}$ & $\mathbf{0 . 9}$ & $\mathbf{1 . 2}$ \\
percent of NMS-8 & 43 & 100 & 43 \\
percent of EU-15 & 62 & 104 & 59 \\
\hline
\end{tabular}

Sources: Fund staff estimates of standard deviations are based on Eurostat data.

A simple simulation suggests that mild output growth volatility in Slovenia does not fully explain the relatively modest variation in primary spending. To assess the impact of smoother growth performance on spending volatility, Table 2 outlines an exercise that holds the volatility ratio between primary spending and the output gap fixed at the observed level of 1.2 but assumes a more volatile output gap matching the NMS- 8 average of 0.9 . Although this experiment suggests that the variation in primary spending in Slovenia would have been higher by more than 50 percent in this scenario, it remains less than half as volatile as the actual NMS-8 average (Table 5 simulation). In other words, the relatively smooth growth performance in Slovenia appears to be an insufficient explanation for the overall pattern of expenditure stability summarized in Table 1 . As a result, other factors are needed to explain spending stability, such as budget rigidities which are the focus of Section B.

\footnotetext{
${ }^{22}$ While primary spending appears relatively volatile in the NMS-8 countries compared to the EU-15 (Table 2), this could reflect structural as well as cyclical factors.
} 


\section{B. Budget Rigidities in Key Sectors}

\section{Health}

The pattern of health spending reflects a blend of discretionary policy targets and budget rigidities. The medium-term health financing strategy of the Health Insurance Institute of Slovenia (HIIS) envisaged an upper threshold in public health spending of about 6.9 percent of GDP over the medium term. This discretionary target effectively anchored the health budget by motivating initiatives to contain employee compensation and accommodate cost pressures from pharmaceuticals and medical equipment. As a result, the stability of health spending as a share of GDP (solid line in Figure 8) masks potential underlying flexibility as the composition of health spending changed (circled area). This finding underscores that discretionary policies to maintain stable spending are observationally equivalent to budget rigidity. But the changes in the composition of health spending during 2002-03 are not all due to budget flexibility. Instead, a large share of this apparent flexibility can be linked to a shift in the accounting of pharmaceutical expenses.

\section{Figure 8. Slovenia: Composition of General Government Health Spending, 2000-04 \\ (As a share of GDP)}

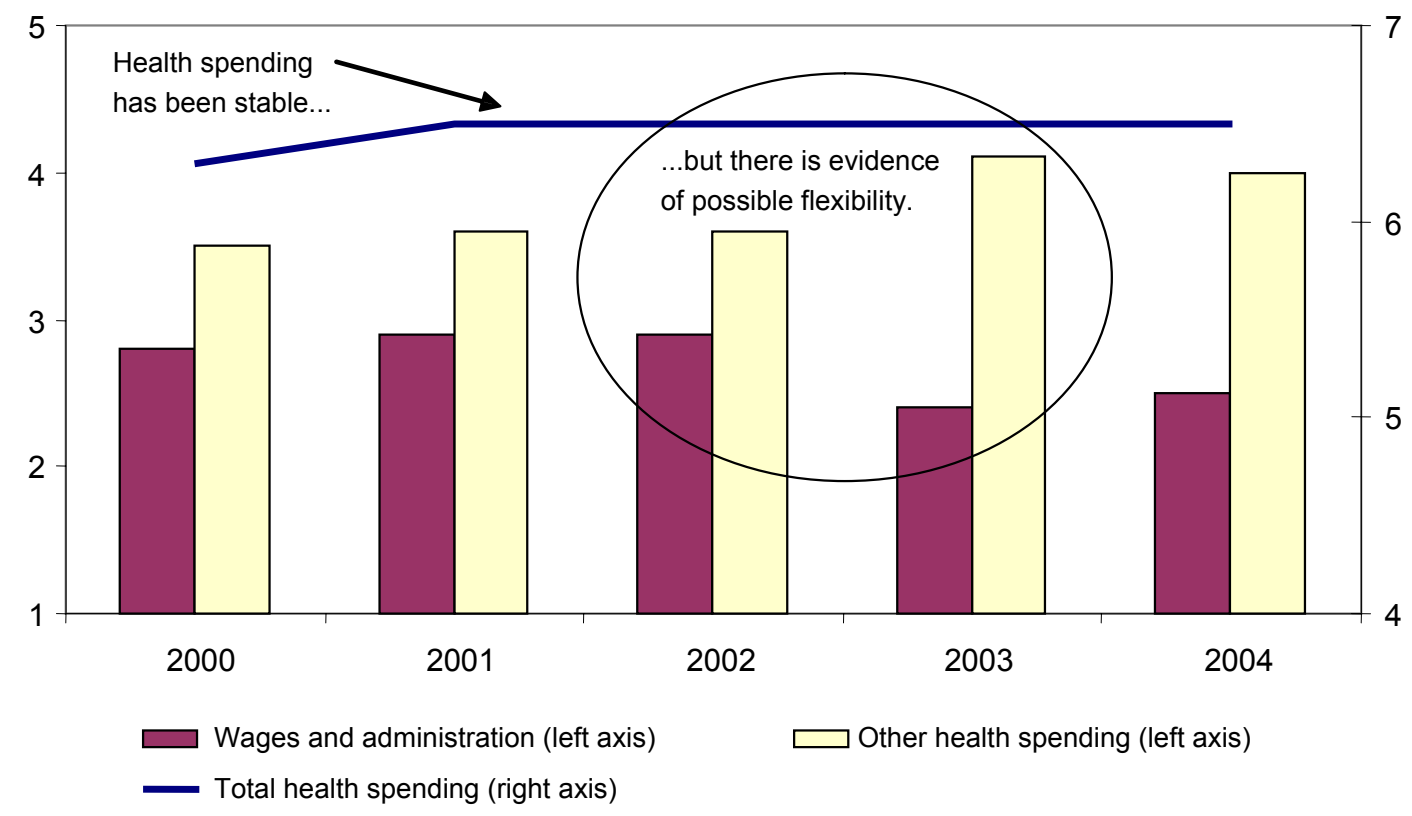

Source: Slovenian state budget

Despite potential flexibility in health spending, there are also significant rigidities that limit the discretionary room to trim spending. For instance, the quasi-autonomous legal status of hospitals constrains government efforts to rationalize costs. Moreover, the costs of primary health clinics established by local governments are difficult for the central government to control; yet the central government must cover their operating expenses, including wages. 
The funding and compensation mechanisms for hospitals and health care providers are another source of rigidity that limits discretionary spending variation. Annual collective bargaining determines the scope of activities and volume of services to be carried out by public health care providers, which comprise 80 percent of total health care providers (Chakraborty, Bultman, and Chawla, 2005). For instance, hospital transfers are based on collectively agreed rates of compensation for treating various medical diagnoses as recorded by the DRGs system. ${ }^{23}$ In addition, the compensation scheme for primary care doctors depends on a collectively agreed capitation rule adjusted for factors, such as age, that affect the average cost of service delivery. ${ }^{24}$ These schemes mean that the government lacks shortterm discretionary scope to adjust health care spending without reopening collective agreements or adjusting compensation rates. ${ }^{25}$

\section{Education}

The relatively high share of compensation to employees compared to other EU countries is an important rigidity that constrains the discretionary scope to adjust short-term education spending (Figure 3). Institutional and funding mechanisms have also fostered rigidities. For instance, local governments establish primary schools, while the federal government finances a significant share of their operational and employment costs. Since these facilities typically serve multiple community functions, local governments are reticent to rationalize excess facilities despite high overhead costs. In addition, the federal funding mechanism does not provide a strong financial incentive to rationalize excess capacity. Funding of the primary school system is generally based on the number of departments or classrooms rather than a per capita-based formula linked to the average cost of service delivery. Although secondary schools are directly controlled by the central government, funding arrangements are still gradually shifting toward per capita-based formulas. Similarly, a significant share of federal transfers to universities is set according to an incremental-cost budgeting formula, constraining discretionary room to adjust spending.

\section{Social protection transfers}

The wide coverage and weak targeting of social benefits compared to other EU countries represent major budget rigidities. For instance, the duration of maternity leave, child

\footnotetext{
${ }^{23}$ The DRG system was implemented during 2002-04 and is now operating in all 19 acute-care hospitals.

${ }^{24}$ There is also a minimum service requirement, however most service providers easily fulfill this condition. Deviations from budgeted compensation also depends on an incentive and penalty scheme to discourage an overprescription of medication and over-referral of patients to secondary care specialists relative to the norm. Although individual compensation varies by 50 percent, overall health spending is generally within 3 percent of the budget target.

${ }^{25}$ Although there might be strong efficiency-oriented reasons to structure health care financing in this manner as discussed in section IV, the implication of the arrangement is that the funding mechanism limits the scope to reduce health care spending in the short term on a discretionary basis. This problem points to a potential tradeoff between greater budget flexibility and efficiency in some circumstances.
} 
allowances and unemployment benefits are on the high side compared to other NMS-8 countries and most EU-15 countries (Table 6). Moreover, pension benefits represent about three quarters of total social protection outlays. This adds further rigidity to overall social spending, as pension reforms typically reduce spending with a long lag. Another concern is the wide coverage of poorly targeted social benefits that weakens the counter cyclicality of spending. Political resistance is perhaps the greatest rigidity in terms of reducing generous social entitlements, given the strong consensus-driven approach to policymaking in Slovenia.

\section{Table 6. Benefit and Duration of Key Social Benefits in Selected EU Countries}

\begin{tabular}{|c|c|c|c|c|c|c|}
\hline & \multicolumn{2}{|c|}{ Maternity Leave Benefit } & \multicolumn{2}{|c|}{ Child Allowance } & \multicolumn{2}{|c|}{ Unemployment Benefit } \\
\hline & $\begin{array}{l}\text { Benefit } \\
\text { (percent of } \\
\text { earnings) }\end{array}$ & $\begin{array}{l}\text { Duration } \\
\text { of benefit } \\
\text { (weeks) }\end{array}$ & $\begin{array}{l}\text { Duration } \\
\text { of benefit } \\
\text { (age limit) }\end{array}$ & $\begin{array}{l}\text { Duration if } \\
\text { student } \\
\text { (age limit) }\end{array}$ & $\begin{array}{l}\text { Benefit } \\
\text { (percent of } \\
\text { earnings) }\end{array}$ & $\begin{array}{l}\text { Duration } \\
\text { of benefit } \\
\text { (months) }\end{array}$ \\
\hline Slovenia & 100 percent & 52 & 18 & 26 & $60-70$ percent & $3-24$ \\
\hline \multicolumn{7}{|l|}{ NMS-8 } \\
\hline Czech Republic & $\ldots 1 /$ & $28-37$ & 26 & 26 & $40-50$ percent & $\ldots$ \\
\hline Estonia & 100 percent & $20-22$ & 16 & 18 & $\ldots$ & 6 \\
\hline Hungary & 70 percent & 24 & 16 & 20 & 65 percent & 9 \\
\hline Latvia & 100 percent & 16 & 14 & 20 & 50 percent & 9 \\
\hline Lithuania & 100 percent & 18 & $\ldots$ & $\ldots$ & $\ldots$ & 6 \\
\hline Slovak Republic & $\ldots$ & 28 & $\ldots$ & $\ldots$ & $\ldots$ & 6 \\
\hline Poland & 100 percent & 16 & 18 & 21 & $\ldots$ & $6-18$ \\
\hline \multicolumn{7}{|l|}{ EU-15 } \\
\hline Austria & 100 percent & 16 & 18 & 26 & 55 percent & $20-52$ \\
\hline Denmark & $\ldots$ & 52 & 18 & 18 & $\ldots$ & 52 \\
\hline France & 100 percent & $16-34$ & 20 & $\ldots$ & $\ldots$ & $4-60$ \\
\hline Germany & 100 percent & 14 & 18 & 27 & $60-67$ percent & $3-32$ \\
\hline UK & $\begin{array}{l}90 \text { percent } \\
\text { for } 6 \text { weeks }\end{array}$ & 26 & 16 & 19 & $\ldots$ & 6 \\
\hline
\end{tabular}

Source: US Social Security Administration (www.ssa.gov/policy/docs/progdesc/ssptw/).

$1 /$ The "..." symbol indicates a missing data observation.

Multiple and complex indexation rules have also contributed to social spending rigidity. Prior to 2007 , multiple indexation formulas pertaining to different social benefits resulted in different real benefit levels over time. These rules also increased administrative costs. Indexation formulas are another potential source of budget rigidity to the extent that the key variables are beyond direct government control, such as foreign price indices, exchange rates or private-sector wage growth. As a result, the recent reform in 2007 to reindex social benefits to inflation is a welcome step.

\section{Compensation to employees}

The strong collective bargaining tradition in Slovenia imposes an important rigidity that constrains short-term expenditure flexibility. The civil service grew by one-third during 1992-2004 and one study estimated that the average wage is 34 percent higher than 
comparable private sector wages (Kastelec, 2005), even though stronger job security in the civil service typically allows for a discount of 10-20 percent relative to private sector wages. ${ }^{26}$ In addition, centralized personnel management fosters additional rigidities, such as fixing the number of civil service positions, centralizing pay scales, and effectively providing tenure to civil servants (Davies, Verhoeven, and Gunnarsson, 2006). The seniority-based system of career advancement also introduces an upward bias in the wage bill as the civil service ages. However, Davies, Verhoeven, and Gunnarsson (2006) demonstrated that wages and salaries are not inherently rigid to adjustment, as widely perceived, suggesting that scope remains to reduce the wage bill significantly over the medium term.

\section{Initial Steps to Enhance Budget Flexibility}

Slovenia could enhance budget flexibility by reforming institutions and the financing mechanism for social services, and accelerating the adoption of flexible work arrangements and performance-based budgeting. The following measures could enhance the country's flexibility to facilitate medium-term expenditure rationalization and offset pressure to compress public investment and other goods and services: ${ }^{27}$

- Implementing institutional reforms. Consolidating indirect budget users such as hospitals and schools in the budget process would enhance the government's ability to contain costs.

- $\quad$ Reforming social services financing. The funding mechanisms for health and education should provide incentives to rationalize excess capacity. For instance, education financing at all levels should increasingly shift towards per capita-based formula to penalize spending units with high relative costs.

- $\quad$ Targeting social benefits. Improved targeting of social benefits would direct additional resources to low-income households while fostering greater counter cyclicality in overall expenditure. The long duration and wide coverage of social benefits should also be carefully reviewed.

- Accelerating flexible work arrangements. Plans to increase flexible and part-time employment arrangements in the civil service should be accelerated to enhance budget flexibility. For instance, fixed-term contracts in primary education could facilitate medium-term consolidation, given the declining primary school-age population and excess number of teachers in that sector.

\footnotetext{
${ }^{26}$ The social agreement approach to collective bargaining is not without benefits, as the previous agreement restrained real wages below productivity growth to facilitate a smooth adoption of the Euro.

${ }^{27}$ Compression of capital spending can lead to under-investment in infrastructure and hinder medium-term growth (see Public Investment and Fiscal Policy-Lessons from the Pilot Studies, IMF, 2005).
} 
- $\quad$ Adopting performance-based budgeting. Implementing performance-based budgeting can expand managerial flexibility in reallocating inputs to better achieve performance targets.

Carrying out institutional reforms and revising the funding mechanisms for social services could require a review of intergovernmental fiscal relations and budget coverage. Indirect budget users with multiple revenue sources and possibly quasi-autonomous legal status should be consolidated and integrated in the state and local budget process as appropriate. The exact delineation of spending units to either the state or local budget should be consistent with intergovernmental expenditure assignments and the financing mechanism, which might need to be updated. A review of the Budget System Law is one possible modality to address this issue. The federal government would need to proceed cautiously to minimize potential service disruption. The next section turns from the need to address budget rigidities to a methodology that can guide medium-term expenditure rationalization based on the relative efficiency of public spending in key areas.

\section{Conclusion}

This paper demonstrated that public spending in Slovenia is relatively inefficient, inflexible, and poorly targeted. These findings suggest that there is scope to trim expenditure without sacrificing outcomes in health, education, and social protection. In order to increase efficiency, the challenge moving forward will be "doing more with less" so as to maintain or even improve performance outcomes. Slovenia appears to perform inefficiently due to its high spending rather than weak outcomes. Institutional reforms that consolidate indirect spending units in the budget process could unlock new savings. Implementing performancebased budgeting could also enhance managerial flexibility and efficiency. In addition, reforms to the health care and education financing mechanism to encourage the rationalization of inefficient service providers with high overhead costs should be considered.

A key initial step in this process will be to address budget rigidities that constrain the scope to adjust spending. Rigidities will exert upward pressure on spending over the medium term unless measures are taken to offset new spending demands. Moreover, continued inflexibility would shift the burden of expenditure consolidation to traditionally flexible areas of the budget or result in poorly targeted across-the-board cuts. These measures can be distortionary and unsustainable over time, as they lead to underinvestment in infrastructure and a deterioration of public services. To enhance budget flexibility implementing flexible work arrangements and rationalizing excess capacity should be accelerated. Collective wage bargaining and centralized personnel management limits the scope to adjust the wage bill over the short term. In addition, the funding mechanism of quasi-autonomous institutions, such as hospitals, health clinics, primary schools, and universities should be carefully reviewed to encourage the rationalization of excess capacity as appropriate and identify scope to enhance spending flexibility.

High social protection spending that has yielded moderate outcomes points to the need for strengthened targeting. Initial steps in this direction include expanding cost recovery of 
preprimary child care and allowing higher university tuitions. Scholarships should be means tested so that overall spending can be lowered and redirected toward low-income students. In this manner, cost recovery need not prevent access to higher education. The wide coverage and long duration of social benefits compared to other NMS-8 and most EU-15 countries should also be carefully reviewed to improve targeting and redirect resources to those households most in need. 


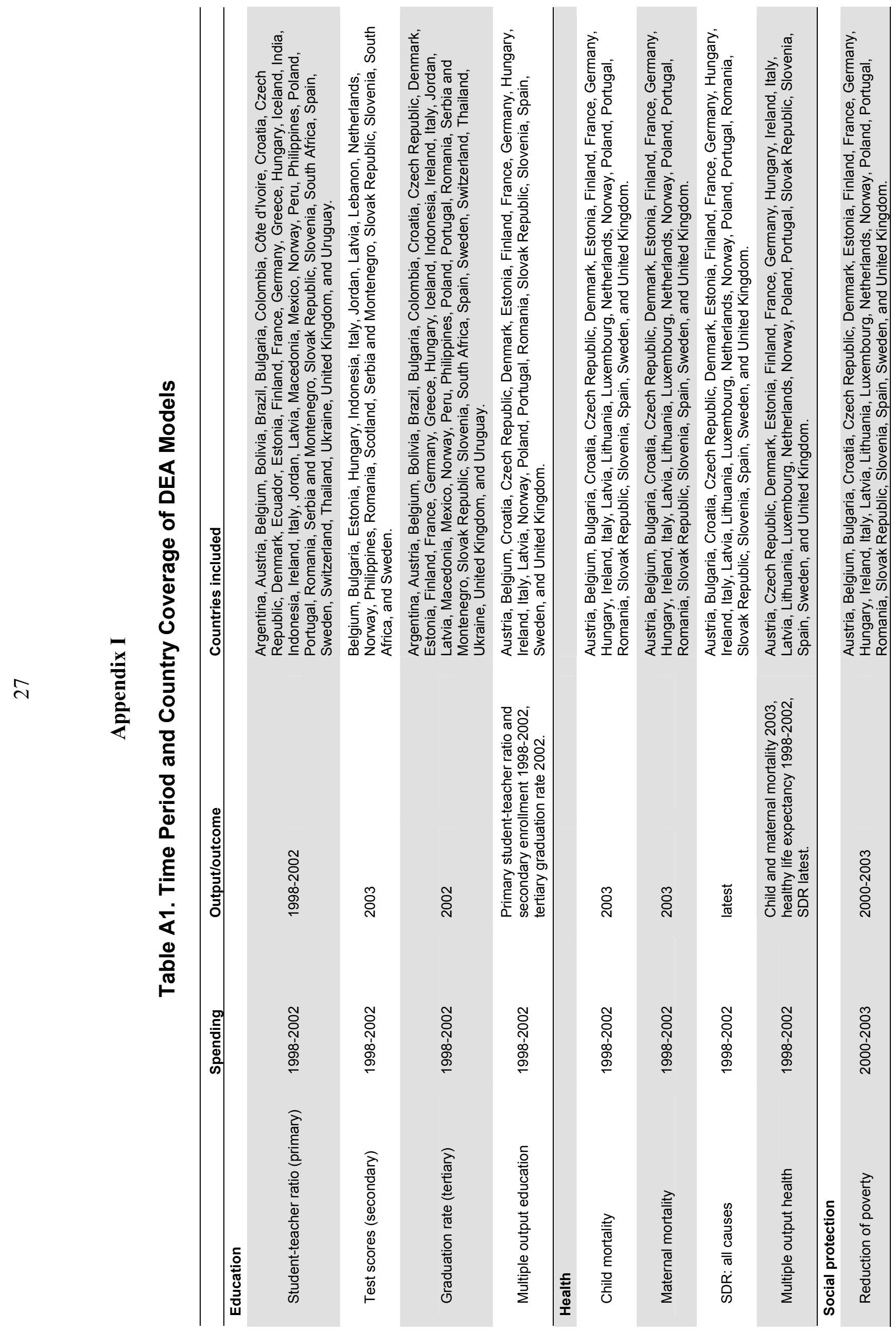




\section{References}

Afonso, A., L. Schuknecht, and V. Tanzi, 2006, "Public Sector Efficiency: Evidence for New EU Member States and Emerging Markets," European Central Bank Working Paper Series No. 581, (Frankfurt: European Central Bank).

Afonso, A., and M. St. Aubyn, 2004, "Non-Parametric Approaches to Education and Health: Expenditure Efficiency in OECD Countries," mimeo, (Lisbon: Technical University of Lisbon).

Alier, M., 2006, "Measuring Budget Rigidities in Latin America," IMF Working Paper, forthcoming, (Washington: International Monetary Fund).

Chakraborty, S., J. Bultman, and M. Chawla, 2005, "Fiscal Challenges in the Health Sector in Slovenia: Managing Expenditures and Reducing Indebtedness," (Washington: World Bank).

Charnes, A., W. Cooper, and E. Rhodes, 1978, "Measuring Efficiency of Decision-Making Units," European Journal of Operational Research, 3, pp. 429-44.

Davies, M., M. Verhoeven, and V. Gunnarsson, 2006, "Wage Bill Inflexibility and Performance Budgeting in Low-Income Countries," (unpublished; Washington: International Monetary Fund).

Farrell, M., 1957, "The Measurement of Productive Efficiency," Journal of the Royal Statistical Society, Series A, Vol. 120, No.3, pp. 253-90.

Gupta, S., and M. Verhoeven, 2001, "The Efficiency of Government Expenditure: Experiences from Africa," Journal of Policy Modeling, No. 23, pp. 433-67.

Herrera, S., and G. Pang, 2005, "Efficiency of Public Spending in Developing Countries: an Efficiency Frontier Approach," World Bank Policy Research Working Paper 3645, (Washington: World Bank).

Hodrick, R.J., and E. C. Prescott, 1997, "Postwar US Business Cycles: an Empirical Investigation," Journal of Money Credit and Banking, Vol. 29, No. 1, pp. 1-16.

International Monetary Fund, 2005, "Public Investment and Fiscal Policy-Lessons from the Pilot Country Studies," (Washington: International Monetary Fund) available at http://www.imf.org/external/np/pp/eng/2005/040105a.htm.

Kastelec, A. S., 2005, "Public Expenditure in Slovenia: Past Trends and Current Issues," Banka Slovenije Prikazi in analize XIII/2, (Ljubljana: Bank of Slovenia). 
Schadler, S., P. Drummond, L. Kuijs, Z. Murgasova, and R. van Elkan, 2005, "Adopting the Euro in Central Europe: Challenges of the Next Step in European Integration," IMF Occasional Paper 234 (Washington: International Monetary Fund).

Simar, L., and P. Wilson, 2007, "Estimation and Inference in Two-stage, Semi-parametric Models of Production Processes.” Journal of Econometrics, 136, pp. 31-64.

Tajnikar, M., and P.D. Bonča, 2005, "The Development of Voluntary Health Insurance and Its Role within the Health Care System in Slovenia," (unpublished; Ljubljana: University of Ljubljana).

Zhu, J., 2003, Quantitative Models for Performance Evaluation and Benchmarking (New York: Springer Science+Business Media Inc.). 